\title{
EKONOMI ISLAM GLOBAL DALAM RANAH FIQH
}

\author{
Abdul Mujib \\ Dosen Perbankan Syariah \\ Universitas Muhammadiyah Surabaya
}

\begin{abstract}
Abstrak
Salah satu kemunculan sistem ekonomi Islam dipicu oleh ketidakpuasan terhadap sistem kapitalisme yang menjadi perekonomian global dikarenakan kebutuhan terhadap ekonomi Islam semakin mendesak seiring perkembangan zaman dan pengaruh barat dalam memasarkan ekonomi kapitalis, sehingga ummat islam mengambil langkah untuk menghindari prilaku sistem kapitalis yang hampir keseluruh aspek sistem ekonomi, namun masih ada kesulitan dalam perjalanannya karena dikalangan masyarakat muslim masih terdapat kesalah pahaman mengenai ekonomi islam, mereka masih menganggap ekonomi islam hanya sistem ekonomi konvensional yang dipoles agar tampak islami. Walau sebenernya sistem ekonomin islam sudah lama berkembang sejak periode islam klasik dengan munculnya pemikiran ekonomi dalam Islam secara serius dan mendalam lewat kajian fiqh muamalah.
\end{abstract}

Kata kunci: Ekonomi Islam, Fiqh 


\section{Pendahuluan}

Jika berbicara mengenai islam maka yang terlintas dalam benak masyarakat adalah FiqhUbudiyahseperti shalat, puasa, zakat dan haji padahal Islam sudah mengatur kehidupan manusia secara totalitas (kafah/global), universal dan komprehensif. Islam mengatur semua aspek kehidupan manusia baik berkaitan dengan masalah keduniaan dan masalah akhirat. ${ }^{1}$ Seirirng pertumbuhan intelektual terhadap perkembangan ekonomi islam, dengan dianggapnya ekonomi konvensional gagal dalam mewujudkan keadilan dan kesejahteraan sosial, melalui penelusuran kembali atau penafsiran ulang terhadap literatur islam dalam alquran, hadist, kitab-kitab figh, dan praktek-praktek ekonomi dimasa rasulullah dan kholifah yang berpegang pada prinsipprinsip syariah serta hasil ijtihad para ulama dan metodelogi yang mereka terapkan dalam menyelesaikan problematika ekonomi yang terjadi dizamannnya.

Salah satu kemunculan sistem ekonomi Islam dipicu oleh ketidakpuasan terhadap sistem kapitalisme yang menjadi perekonomian global dikarenakan kebutuhan terhadap ekonomi Islam semakin mendesak seiring perkembangan zaman dan pengaruh barat dalam memasarkan ekonomi kapitalis, sehingga ummat islam mengambil langkah untuk menghindari prilaku sistem kapitalis yang hampir keseluruh aspek sistem ekonomi, namun masih ada kesulitan dalam perjalanannya karena dikalangan masyarakat muslim masih terdapat kesalah pahaman mengenai ekonomi islam, mereka masih menganggap ekonomi islam hanya sistem ekonomi konvensional yang dipoles agar tampak islami. Walau sebenernya sistem ekonomin islam sudah lama berkembang sejak periode islam klasik dengan munculnya pemikiran ekonomi dalam Islam secara serius dan mendalam lewat kajian fiqh muamalah. Secara global, kekuatan ekonomi di bawah sistem kapitalisme telah menyisakan sejumlah problem dalam kaitannya dengan keadilan ekonomi, baik dalam soal relasi kepemilikan, produksi, konsumsi dan distribusi. Di bawah sistem-sistem ini, manusia modern menghadapi persoalan ketidakadilan sosial, kesenjangan pendapatan, kemiskinan, diskriminasi, marjinalisasi, korupsi dan sebagainya. ${ }^{2}$ Diharapkan dengan hadirnya ekonomi Islam akan menjadi alternatif bagi persoalan-persoalan tersebut dengan berpedoman pada nilai-nilai dan prinsip-prinsip Islam.

\footnotetext{
${ }^{1}$ Ismail Nawawi, Isu-Isu Ekonomi Islam: kompilasi Pemmikiran dan teori menuju praktik di tengah arus ekonomi global Buku 1 Nalar Filsafat (Jakarta, VivPres 2013). Hal. 1

2 Joseph. Carens, Equality Moral Incentives and the Market, (Chicago University Press, 1981). hal. 2-5
} 


\section{Pengertian Islam}

Kata islam berasal dari bahsa arab yang secara etimologi mengandung makna sejahtera, tidak cacat, selamat, kedamaian, kepatuhan dan penyerahan diri.Patuh dan ta'at kepada Allah disebut sebagai orang Muslim. Dari uraian tersebut dapat disimpulkan Islam dari segi kebahasan adalah patuh, tunduk, dan ta'at kepada Allah dalam upaya mencari keselamatan dan kebahagiaan hidup di dunia dan akhirat. $\mathrm{Hal}$ itu dilakukan atas kesadarn dan kemauan diri sendiri, bukan paksaan atau berpura-pura, melainkan sebagai panggilan dari fitrah dirinya sebagai makhluk yang sejak dalam kandungan telah menyatakan patuh dan tunduk kepada Allah.

Secara teoritas Islam adalah agama yang diwahyukan Tuhan kepada manusia melalui Muhammad sebagai Rasul. Islam pada hakikatnya membawa ajarannya yang bukan hanya mengenai berbagai segi dari kehidupan manusia. Sumber ajaran yang mengambil berbagai aspek adalah Al-Qur'an dan hadist. Sumber-sumber ajaran Islam yang merupakan bagian pilar penting kajian Islam dimunculkan agar dikursuskan dan paradigma keislaman tidak keluar dari sumber alinya, yaitu Al-Qur'an dan hadits ${ }^{3}$

\section{Pengertian Ekonomi}

Istilah Ekonomi muncul beratus-ratus tahun yang lalu,sebelum kelahiran Nabi Isa, entah pada zaman apa,pada pemerintahan raja siapa, serta oleh siapakah istilah ekonomi itu pertama kali dilontarkan, tidak ada orang yang pasti mengetahuinya, yang jelas hanyalah bahwa istilah ekonomi berasal dari dari kata-kata yunani, asal katanya adalah Oikosberarti keluarga atau rumah tangga Nomos berarti peraturan atau aturan. Sedangkan menurut Istilah yaitu manajemen rumah tangga atau peraturan rumah tangga, alangkah sulitnya mencari terjemahannya yang tepat untuk kata-kata itu, tetapi pada kesulitannya orang-orang barat menerjemahkan dengan management of household or estate (tata laksana rumah tangga atau pemilikan).

Pengertian ekonomi itu sendiri adalah salah satu bidang ilmu sosial yang membahas dan mempelajari tentang kegiatan manusia berkaitan langsung dengan distribusi, konsumsi dan produksi pada barang dan jasa. $^{4}$ Dari pengertian diatas secara umum, dapat dikatakan bahwa pengertian ekonomi adalah sebuah bidang kajian ilmu yang berhubungan

\footnotetext{
${ }^{3}$ Shonhaji Sholeh, dkk. pengantar study Islam, I (Surabaya, Sunan Ampel Press, 2010). Hal 10

${ }^{4}$ Suherman Rosyidi, Pengantar Teori Ekonomi: Pendekatan pada teori ekonomi mikro dan makro, (Jakarta, PT RajaGrafindo Persada, 2006). Hal. 5
} 
tentang pengurusan sumber daya material individu, masyarakat dan negara untuk meningkatkan kesejahteraan kehidupan manusia. Karena ittulah, ekonomi merupakan salah satu ilmu yang berkaitan tenatang tindakan dan prilaku manusia dalam memenuhi kebutuha hidupnya yang berkembang dengan sumber daya yang ada melalui kegiatan, konsumsi, produksi dan distribusi. $^{5}$

\section{Ekonomi dalam Lingkup Hukum Islam}

Islam sebagai agama mengatur kehidupan manusia secara universal baik hubungan dengan Allah (Hablumminallah) maupun dalam hubungan sesama manusia (Hablumminannas)Secara komprehensif hukum tidak ditetapkan hanya untuk seorang individu tanpa keluarga, dan tidak ditetapkan hanya untuk satu keluarga tanpa masyarakat, bukan pula untuk masyarakat secara terpisah dari masyarakat lainnya dalam lingkup ummat islam, dan tidak pula ditetapkan hanya untuk satu bangasa secara terpisah dari bangsa-bangsa lainnya, baik bangsa penganut agama ahlul kitab maupun penyembah berhala. ${ }^{6}$

Ada tiga pilar pokok dalam ajaran islam sebagaimana di atas, yang akan di jabarkan sebagaimana berikut: $^{7}$

1. Aqidah adalah komponen ajaran Islam yang mengatur atas keyakinan tentang keberadaan Allah, sehingga harus menjadi keimanan seorang muslim manakala melakukan aktifitas dimuka bumi semata-mata untuk mencapai keridhoan Allah.

2. Syariah adalah komponen ajaran islam yang mengatur tentang kehdupan seorang muslim baik berkaitan dengan ibadah (hablumminallah) maupun dalam bidang muamalah (hablumminnas), yang merupakan katalisasi Aqidah yang menjadi keyakinannya. Sementara itu muamalah meliputi berbagai bidang kehidupan antara lain mencakup ekonomi atau harta perniagaan yang disebut muamalah maliyah.

3. Akhlak adalah landasan prilaku dan kepribadian yang akan mencirikan dirinya sebagai seorang muslim yang taat berdasarkan syariah dan aqidah yang menjdi pedoman hidup yang disebut akhlakul karimah, sebagaimana hadist nabi yang menyatakan " tidak sekitranya aku diutus kecuali menjadikan akhlakul karimah"

\footnotetext{
${ }^{5}$ Dikutip dari, http//:isma-ismi.com/pengertian-ekonomi.html. 7-november-2015

${ }^{6}$ Ismail Nawawi, Isu-Isu Ekonomi Islam: kompilasi Pemmikiran dan teori menuju praktik di tengah arus ekonomi global Buku 1 Nalar Filsafat (Jakarta, VivPres 2013). Hal. 19
}

${ }^{7}$ Ibid. Hal 20 


\section{Sumber Hukum Islam}

Sudah jelas jika berbicara mengenai sumber-sumber hukum Islam sebagaimana berikut:

\section{Al-Quran}

Kata Al-Quran dari segi bahasa bentuk masdar dari kata qara'a yang masuk pada wajan fu'lan yang berati bacaan atau apa yang tertulis padanya, maqru' sesuai yang terdapat dalam surat Al-Qiyamah: Yang artinya " sesungguhnya atas tanggungan kami-lah mengumpulkan (di dalamnya) dan (membuatmu pandai) membacanya. Apabila kami telah selesai membacanya, maka ikutilah bacaannya.".

Al-Quran secara terminologi menurut kalangan ulama Ushul fiqh sebagai berikut:Yang artinya:" kalam Allah yang diturunkan kepada nabi muhammad dalam bahasa Arab yang dinukilkan kepada generasi sesudahnya secara mutawattir, membacanya merupakan ibadah,tertulis dalam mushaf, dimulai dari surah AlFatihah dan ditutup dengan surat An-Nas."

\section{Sunah}

Dari segi bahasa sunanhadalah jalan yang biasa dilalui atau suatu cara yang senantiasa dilakukan, tanpa mempermasalahkan, apakah cara tersebut baik atau buruk, arti tersebut sesuai dengan sabda Rasulullah yang berbunyi, Artinya: " barang siapa yang membiasakan sesuatu yang baik di dalam Islam, maka ia menerima pahalanya dan pahala orangorang sesudahnyan yang mengamalkannya. ${ }^{10}$

Secara terminologi perngertian sunah bisa dilihat dari tiga disiplin ilmu:

1. Ilmu Hadist, para ahli hadist mengidentikkaan sunah dengan hadist, yaitu segala sesuatu yang disandarkan kepada Nabi Muhammad, baik perkataan, perbuatan, maupun ketetapannya.

2. IImu Ushul Fiqih, menurut ulama ahli ushul fiqih, sunnah adalah segala yang diriwayatkan dari Nabi Muhammad berupa perbuatan, perkataan dan ketetapan berkaitan dengan bukum.

3. Ilmu Fiqih, pengertian sunah menurut ahli fiqih hampir sama dengan pengertian yang dikemukakan oleh para ahli Ushul

\footnotetext{
${ }^{8}$ Al-quran surat Al-Qiyamah, Ayat 17-18

${ }^{9}$ Rahmat, Syafe'i, Ilmu Ushul Fiqih, (Bandung, CV. Pustaka Setia, 1999). Hal 49

${ }^{10}$ Hadist, Shohih Muslim, Al-Khatib, hal.17
} 
Fiqih. Akan tetapi, istilah sunnah dalam fiqih juga dimaksudkan sebagai salah satu hukum taklifi, yang berarti seuatu perbuatan yang akan mendapatkan pahala bila dikerjakan dan tidak berdosa apabila ditinggalkan. ${ }^{11}$

\section{3. ljma'}

Definisi ijma' menurut bahasa adalah kesepakatan terhadap sesuatu. Suatu kaum dikatakan telah ber-ljma' bila mereka bersepakat terhadap sesuatu, sebagaimana firman Allah dalam Al-Quran yang menerangkan keadaan saudara-saudara Yusuf yang artinya: "maka tatkala mereka membawanya dab sepakat memasukkannya ke dasar sumur (lalu mereka memasukkan dia), dan (diwaktu dia sudah ada di dalam sumur) kami wahyukan kepada Yusuf, "sesungguhnya kamu akan menceritakan kepada mereka perbuatan mereka ini, sedang mereka tiada ingat lagi." ${ }^{\prime 2}$

Sedang para ulama berbeda pendapat dalam mendefinisikan ijma':

Pengarang kitab Fushulul Bada'i berpendapat ljma' adalah kesepakatan semua mujtahid dari ijma' ummat muhammad dalam suatu masa setelah beliau wafat terhadap hukum syara'. Menurut kitab Tahrir, Al-Kamal bin Hamam bahawanya ijma' adalah kesepakatan mujtahidsuatu masa dari ijma' Nabi Muhammad terhadap masalah syara'. ${ }^{13}$

\section{Qiyas}

Menurut bahasa qiyas berarti pengukuran sesuatu dengan yang lainnya atau penyamaan sesuatu dengan yang sejenisnya. Ulama fiqih memberikan definisi berbeda-beda tergantung pandangan mereka terhadap kedudukan qiyas dalam istinbath hukum, mereka membaginya dalam dua golongan berikut:

Golongan pertama mengatakan bahwa qiyas merupakan ciptaan manusia, yakni pandangan mujtahid sedangkan menurut golonga kedua qiyas merupakan ciptaan syari', yakni merupakan dalil hukum yang berdiri sendiri atau merupakan

\footnotetext{
${ }^{11}$ Rahmat, Syafe'i, Ilmu Ushul Fiqih, (Bandung, CV. Pustaka Setia, 1999). Hal 60

${ }^{12}$ Al-Quran Surat Yusuf Ayat 15.

${ }^{13}$ Rahmat, Syafe'i, Ilmu Ushul Fiqih, (Bandung, CV. Pustaka Setia, 1999). Hal 69
} 
hujjat ilahiyah yang dibuat syari; sebagai alat untuk mengetahui seuatu hukum.

Pada pandangan tersebut masing-masing ulama memberikan definisi qiyas sebagai berikut:

1. Shadr Asy-Syari'at menyatakan bahwa qiyas adalah pemindahan hukum yang terdapat pada ashl kepada furu' atas dasar illat yang tidak dapat diketahui dengan logika bahasa.

2. Al-Human menyatakan qiyas adalah persamaan hukum suatu kasus dengan kasus lainnya kareana kesamaan illat hukumnya yang tidak dapat diketahui melalui pemahaman bahasa secara murni.

\section{Ekonomi dan Fiqih Muamalah}

Untuk melihat relasi yang jelas antara fiqih muamalah dengan ekonomi islam. Maka kita harus mengkaji Fiqih muamalah terlebih dahulu yang merupakan salah satu aspek dari hukum Islam.

\section{Fiqih}

Menurut bahasa fiqih adalah paham sedangkan menurut terminologi, fiqih pada mulanya berarti pengetahuan ke agamaan yang mencakup seluruh ajaran agama, baik berupa aqidah, akhlak dan amaliyah, yakni sama dengan arti syariah islamiyah. Namun pada perkembangan selanjutnya, fiqih di artikan sebagai bagian dari syariah islamiyah, yaitu pengetahuan tentang hukum syariah islamiyah yang berkaitan dengan perbuatan manusia yang telah dewasa dan berakal sehat yang diambil dari dalil-dalil yang terperinci.

2. Muamalah

Menurut etimilogi kata muamalah adalah bentuk masdar dari kata Amala yang artinya saling bertindak, saling berbuat, dan saling beramal.

\section{Fiqih Muamalah}

Pengertian fiqih muamalah menurut terminologi dibagi menjadi dua: ${ }^{14}$

a. Pengertian fiqih muamalah dalam arti luas adalah aturanaturan (hukum) Allah yang ditujukan untuk mengatur kehidupan manusia dalam urusan keduniaan atau urusan yang berkaitan dengan urusan duniawi dan sosial kemasyarakatan.

b. Pengertian fiqih muamalah dalam arti sempit lebih menekankan keharusan untuk menaati aturan-aturan Allah

\footnotetext{
${ }^{14}$ Ibid. Hal: 13
} 
yang telah ditetapkan untuk mengatur hubungan atara manusia dengan cara memperoleh, mengatur, mengelola dan mengembangkan harta benda. Namun menurut pengertian muamalah diatas fiqih muamalah tidak mencakup berbagai hal yang berkaitan dengan harta, seperti cara mengatur tirkah (harta waris), sebab masalah ini telah diatur dalam disiplin ilmu itu sendiri, yaitu dalam Fiqh Mawaris.

\section{Pembagian dan Lingkup Kajian Fiqh Muamalah}

Pembagian figh muamalah yang dikemukakanulama fiqh sangat bervariasi tergantung pada sudut pandang meraka memngkonsepsikan dalam pengertian luas dan/atau dalam arti sempit. Ibn Abidin, salah seorang yang mendefinisikan fiqh muamalah dalam arti luas, membagi menjadi lima:

1. Muwadhah Maliyah (Hukum Kebendaan)

2. Munakahat (Hukum Perkawinan)

3. Muhasanat (Hukum Acara)

4. Amanat dan 'Aryah (Pinjaman)

5. Tirkah (Harta Peninggalan)

Sedangkan Al-Fikri dalam kitab Al-Muamalah Al-Madiyah wa Al-Adabiyah, membagi fiqih muamalah menjadi dua:

1. Al-muamalah Al-Madiyah adalah Muamalah yang mengkaji dari segi objeknya yaitu benda. seperti jual beli yang tidak hanya untuk memperolaeh keuntungan semata tetapi untuk memperoleh ridho Allah. Konsekuensinya harus mengikuti tata cara jual beli yang telah ditetapkan syara'.

2. Al-Muamalah Al-Adabiyah adalah muamalah ditinjau dari segi cara tukar menukar benda yang sumbernya dari panca indra manusia, sedangkan unsur-unsur penegaknya adalah hak dan kewajiban. Seperti jujur, hasud, iri, dendam dan lain-lain.

\section{Ekonomi Islam}

Demi untuk memahami prinsip-prinsip ekonomi Islam dan pengembangan pemikiran pengetahuan tentang sumber-sumber yang membentuk sumber utama inspirasi bagi ekonomi Islam adalah alQur'andan As-Sunah Nabi Muhammad sebagai penguasa dan pemimpin umat secara khusus menaruh perhatian besar terhadap persoalan keadilan dan hak-hak ekonomi.

Ekonomi Islam bukan sekedar ekonomi syariah, melainkan ekonomi yang melambangkan peradaban Islam yang mempunyai spektrum begitu 
luas. Dalam hal ini, kaitan ekonomi islam dengan ilmu-ilmu islam lainnya jelas bukan hanya dengan ilmu fiqih saja, melainkan dengan ilmu-ilmu lain yang terkait dengan peradaban itu sendiri.

ekonomi Islam memiliki dua aspek, yaitu aspek permanen dan aspek perubahan. Aspek permanen bertautan dengan prinsip, yakni sehimpunan dasar-dasar dan prinsip-prinsip ekonomi yang diajarkan oleh al-Qur'an dan Sunah untuk diimplementasikan oleh umat Islam dalam setiap ruang dan waktu terlepas dari tingkat perkembangan perekonomian suatu masyarakat dan bentuk-bentuk produksi yang dominan pada suatu masa. Sedangkan aspek perubahan berkaitan dengan tataran aplikatif ekonomi syariah, yakni berupa kebijakan praktis dan analisis yang diformulasikan oleh para ulama dan pemikir ekonomi syariah untuk mentransformasikan dasar-dasar dan prinsip-prinsip ekonomi syariah dalam realitas empirik masyarakat Islam. ${ }^{15}$

Sedangkan Anas Zarqa menegaskan bahwa hubungan antara ekonomi islam dan fiqih muamalah dapat dilihat dari tiga fungsi utama:

1. Ekonomi Islam memiliki fungsi deskripsi dan identifikasi faktafakta, penemuan terhadap hubungan dan hukum-hukum yang menghubungkan fenomena ekonomi secara serentak, dan mengupayakan manfaat ekonomis diantara ketentuan-ketentuan syariah atau mennetukan akibat ekonomis baik dalam jangka pendek maupun jangka panjang. Sedangkan fiqih muamalah melihat fenomena ekonomi dari aspek yang normatif yakni bagaimana aturan syariah terhadap fenomena tersebut kemudian menetapkan kebolehan dan larangan tergantung fenomena dan fakta yang dihadapi

2. Join fungsi antara fiqih muamalah dengan ekonomi islam dalam hal ini, adalah formulasi terhadap kebijakan-kebijakan ekonomi dan ketentuan-ketentuan yang berkaitan dengan kesejahteraan publik, seperti contoh kebijakan fiskal dan perbendaharaan negara.

3. Fungsi yang mendukung fiqih. Dalam hal ini adalah suatu fungsi dalam rangka membentuk fiqih sampai pada pemahaman terhadap aturan syariah yang semestinya dalam kasus-kasus tertentu, dimana faktor ekonomi dapat berperan dalam menentukan diantara beberapa aturan yang mungkin lebih

${ }^{15}$ Muhammad Syauqi al- Fanjari, Nahwa Iqtisad Islami: al-Manhaj wa al-Mafhum, ( Dar al-Zayidi li al-Thiba'ah wa al-Nasyr, t.th). hal. 12 
relevan untuk diterpkan dari pada yang lain. Misalnya kasus perdagangan internasional. ${ }^{16}$

\section{DAFATAR PUSTAKA}

Fanjari, Muhammad Syauqi Nahwa lqtisad Islami: al-Manhaj wa alMafhum, (Dar al-Zayidi li al-Thiba'ah wa al-Nasyr, t.th).

Al-Quran, kementrian Agama RI Mushaf Al-Quran Terjemah, (Tangearang, PT. Indah Kiat Pulp \& Paper Tbk, 2009).

Carens,Joseph, Equality Moral Incentives and the Market, (Chicago University Press, 1981)

Dikutip dari, http//isma-ismi.com/pengertian-ekonomi.html

Nawawi,Ismail, Isu-Isu Ekonomi Islam: kompilasi Pemmikiran dan teori menuju praktik di tengah arus ekonomi global Buku 1 Nalar Filsafat (Jakarta, VivPres, 2013)

Rosyidi ,Suherman, Pengantar Teori Ekonomi: Pendekatan pada teori ekonomi mikro dan makro, (Jakarta, PT RajaGrafindo Persada, 2006).

Sholeh, Shonhaji dkk. pengantar study Islam, I (Surabaya, Sunan Ampel Press,2010)

Syafe'i, Rahmat, IImu Ushul Fiqih, (Bandung, CV. Pustaka Setia, 1999)

Zarqa, Anas, Achiving The Islamization of Eonomics: Concept and Methodelogy.(t.tp,t.th ).

16 Anas Zarqa, Achiving The Islamization of Ekonomics: Concept and Methodelogy.(t.tp,t.th ). Hal. 10 